\title{
NAJSTARSZY TEKST "VITA S. PAULI PRIMI EREMITAE" ŚW. HIERONIMA
}

Z trzech dzleł biograficznych napisanych przez św. Hieronima: Vita Sanct1 Pauli primi eremitae, Vita Sancti Hilarionis, Vita Malchi monachi captivi, pierwsze uwazane jest powszechnie za najstarsze. zywot ten powstał przed rokiem 380, prawdopodobnie podczas pobytu Dalmaty na pustyn1 Chalc1s $/ 375-379 /{ }^{1}$.

Hieronimowy rękopis nie zachowal się oczywície do naszych czasów. Samo dzieło jednak przetrwało wielu kodeksach kopiowanych w skryptoriach całej Europy. Mamy wystarczająco wiele przekonywujących dowodów, aby twierdzić, ze Vita Pauli zaczęto kopiować juz bardzo wcześnie. Sam zresztá autor mów1 prawdopodobnie o plerwszej kopli tegoz dzieła, gdy swolm liście do Pawa z Concordia, połozonej między Akwileją a Alatri, pisze przesyłając adresatowi tekst Vita Pauli: "Misimus interim tibi, id est Paulo seni, Paulum seniorem, in quo propter simpliciores quosque multum in delciendo sermone laboravimus ${ }^{2}$. Moźemy chyba słusznie przypuszczać, że Hieronim nle przesłał oryginału dzieła, lecz kopię. Warto nadto przypomnieć, ze Strydonczykowi nie były obce tajniki skryby. W 11 ście bowiem do Florentyna pisał, iz posiada duży księgozbiór, w którym moźna spotkać takze teksty przezeń koplowane ${ }^{3}$. Innym dowodem na to, że Vita Pauli była od.samego początu bardzo rozpowszechniona, a co za tym idzie często kopiowana jeszcze przed napisaniem Vita S.Hilarionis/389-392/, moze byó prolog do tej ostatniej, wtórym Hieronim pisaz o pewnych krytykach jego Vita S. Pauli: "/.../ maledicorum voces contemnimus,

1 Por. B. Negórsk1, Swięty Pawel Pierwszy Pustelnik w świetle tekstów patrystycznych. "Studia Claromontana" 6/1985/110-144, spec。111 1113.

2 H1eronymus, Epistola 10, 3 /Ad Paulum senem Concordiae/, CSEL 54, 38 ; por. takze B. Degórsk1, tanże 124.

3 Por. Hieronymus, Epistola 5, 2, CSEL 54, 22. 
qui olim detrahentes Paulo meo nunc forte detrahent et Hilarioni, illum solitudinis calumniati, huic obilcientes frequentiam; ut qui semper latuit, non fuisse, qui a multis visus est vilis existimeturn ${ }^{4}$. Tak rozpowszechniona krytyka świadczyć może bez wątpienia, iz juz พо́พczas istniazo wiele kopil tegoz dzieła.

Jeżeli chodzi o śwladectwa osób współczesnych Hieronimowi, wspomnieć wypada Paulina, diakona z Mediolanu /+418/, który wymienia Vita Paul1 we wstępie do swego Vita S. Ambrosi1: Hortaris, Venerab1$11 \mathrm{~s}$. Augustine, ut sicut beati viri Athanasius Episcopus et Hieronymus Presbyter stilo prosecuti sunt vitam Sanctorum Pauli et Antonil, in eremo positorum ${ }^{5} / \ldots /$. Ponadto wielu autorów wspomina św. Pawła z Teb, nie wzmiankując jego biografil. Biorąc jednak pod uwagę, że Hieronim był pierwszyn ojceas, który rozpowszechnił postá św. Pawła na Zachodzie, nożemy twierdzić, iż zarówno pisarze jemu współcześni, jak 1 późniejsi zaczerpnęli szczegóły dotyczqce Pawła właśnie z jednej z kopil Vita S. Pauli primi eremitae.

Wielka llość odpisów Vita powodowała z konieczności, iz do tekstu oryginalnego dostawały się obce warianty 1 dodatki czy tez opuszczenia. Z tego to powodu wszystkie najstarsze kodeksy, zawierające Vita S. Pauli, należa do bardzo cennych źródel przy dochodzeniu do formy tekstu mozliwie najblizszej oryginałowi.

Najstarszym kodeksem, zawierającym Vita S. Pauli primi eremitae, który dotarł do naszych czasów, jest pochodzący z 517 r. kodeks Veronensis XXXVIII /36/. Liczy on 118 follałów pergaminowych o wymarach $250 \times 224 \mathrm{~mm}$. Każda strona zawiera 20 lini1, z których każda posiada około 31 liter. Jest to najstarszy rękopis pergaminowy, w którym skryba umieścił dokładną datę jego powstania. Na foliale 107 czytamy: "Incipit Vita Beati Pauli Monachi Thebei".Foliał 117:"Codix[sic]hec [sic] Vverona〉/dopisane u góry/de vita beat[i] martini episcopi et confessoris et beati pauli. Sanctorum sub die Kalendarum augusti agapito viro clarissimo consule indictionis decimae per ursicinum

4 Vita S. Hilarionis 1, Vite dei Santi /A cura di Chr. Mohrmann/, t. 4, Testo critico a cura di A. A. K. Bastiaenses e Jan W. Smit/, Milano 1975, 72174 ; por. B. Degórski, jw. 122.

5 Vita S. Ambrosii 1, PL 14, 27. 
lectorem ecclesiae Veronensis". Kodeks znajduje się nadal w Biblioteca Capitolare $\mathbf{w e r o n i e , ~ g d z i e ~ t e z ~} 1$ powstał. Napisany został pismem "książkowym uncjalnym" 1 nie zaw1era kontrakcj1. Posiada tylko skróty: $q^{\prime}$ zamiast - que 1 - zamiast -m. Follal 112 bardzo wcześnie zaginał; został jednak zastapiony innym, pocbodzącym prawdopodobnie z IX wieku.

Poniewaź nie istnieje zadne wydanie Vita $S$. Pauli, które zawierałoby podzial tekstu na linie, w celu wskazania lekcji charakterystycznych dla Veronensis XXXVIII /36/ posłużym się tekstem Vita Pauli znajdujacym się wydantu Migne'a PL 23, 17-30. Pierwsza cyfra oznaczać będzie rozdzial, druga zaś - kolumnę.

\section{$\underline{\text { PL }}$}

1. sumpsere prinoipium $/ 1,17 /$

2. natus sit /1, 17/

3. In quam opinionem vulgus omne consentit / $17 /$

4. magistri corpus sepelivit, etiam nunc affirmant /1, 18/

5. 1stius ret $/ 1,18 /$

6. hominem fuisse /1, 18/

7. et quas Satanae $/ 1,19 /$

8. martyrium pertulerunt $/ 2,19 /$

9. Christi nomine gladio percuti $/ 2,19 /$

10. ab ipso passus et $/ 2,19 /$

11. non permittebatur /2, 19/

12. subjicimus $/ 2,19 /$

13. eculeos $/ 3,19 /$

14. perungi $/ 3,19 /$

15. religatis mantbus post tergum $/ 3,19 /$

16. Juvenil1 $/ 3,19 /$

17. abduci /3, 19/

6 "qui" $1 \mathrm{~m}$. /ut vid./ sup. 1in.

\section{Veronens is XXXVIII $/ 36 /$}

principia sumpserunt

natus est

in qua opinione omnes consentiunt

corpus magistri sepelivit, qui etiam nunc adfirmat

rei istius

homi nem

vel quas satanae

damnati sunt

eo nomine gladio perpeti

ab eo passus est

non permittebat

subiecimus

eculeum

perfund 1

religatis post tergum manibus

Iuvenali

adduc 1 
18. leni luxta murmure aquarum /3, 19/

19. praestringeret $/ 3,19 /$

20. exstructum plumis lectum resupinari $/ 3,19 /$

21. et quo se verteret, nesciebat. Quem /3, 20/

22. Tandem coelitus inspiratus $/ 3,20 /$

23. succedens doloris magnitudo superavit $/ 3,20 /$

24. Thebaidam $/ 4,20 /$

25. tradita, post mortem /4, 20/

26. locuplet1/4, 20/

27. apprime /4, 20/

28. cum persecutionis procella detonaret, in villam remotiorem et secretiorem secessit /4, 20/

29. $\operatorname{cog} 1$ t Auri sacra Pames /4, 20/

30. ut solet /4, 20/

31. spectans $/ 4,20 /$

32. ab scelere revocavit /4, 20/

33. Quod ubi /5, 21/

34. praestolaretur $/ 5,21 /$

35. progrediens /5, 21/

36. rursusque subsistens atque hoc $/ 5,21 /$.

37. tandem reperit $/ 5,21 /$

38. hominum occulta cognoscere/, avidius explorans $/ 5,21 /$.

39. cujus rivum /5, 21/

40. erumpentem, statim modico foramine $/ 5,21 /$

41. aquas $/ 5,21 /$

42. 1itterae ferunt /5, 21/ lenita murmur

stringeret

structum plumis lectulum supinar1

quo se conferet $\langle e t\rangle$ quem $^{7}$

/om/

succidens $^{8}$ doloris magnitudo

calcavit

thebaidem

tradita morte

locuplem

adplene

dum persecutionis detonaret procella in uilla remotiore secretior $* * * * 9$

cogis auri sacra famis

/om/

expectans

a scelere revocaverunt

quid ubi

praestolatur

procedens

rursusque tandem adque

repper1t

hominum avidius occulta cognoscere cupiens

/om/

/om/

/om/

11tterae fuerunt

$7{ }_{\|} \theta t^{\prime \prime} 2 \mathrm{~m}$. add.

8 "1" 2 m. sup. ras.

9 eras. $2 \mathrm{~m}$. /ut vid./; "erat vel est" $1 \mathrm{~m} . / \mathrm{ut}$ vid./. 
43. qua Cleopatrae junctus est Antonius $/ 5,21 /$

44. quas1 quod $/ 6,21 /$

45. offerretur $/ 6,21 /$

46. ibidem in orationibus $/ 6,21 /$

47. eremi parte /6, 22/

48. et vidisse $/ 6,22 /$

49. per triginta annos $/ 6,22 /$

50. hordeaceo /6, 22/

51. GUBBAM $/ 6,22 /$

52. sustentabatur $/ 6,22 /$

53. Haec 1gitur /6, 22/

54. videbuntur his $/ 6,22 /$

55. redeam $/ 7,22 /$

56. centum tredecim annos $/ 7,22 /$

57. Vitam coelestem /7, 22/

58. perfectum monachum $/ 7,22 /$

59. At i111/7, 22/

60. multo se meliorem / $7,22 /$

61. deberet proficisc1. Illico/7, 22/

62. artus $/ 7,22 /$

63. media dies $/ 7,22 /$

64. abducebatur $/ 7,22 /$

65. In Deum meum $/ 7,22 /$

66. olim conservum $/ 7,22 /$

67. conspicit $/ 7,23 /$

68. mistum $/ 7,23 /$

69. Hippocentauro /7, 23/

70. 1mpressione signi /7, 23/

71. hic servus Dei $/ 7,23 /$

72. Infrendens $/ 7,23 /$

73. setis

74. Et dexterae protensione manus $/ 7,23 /$ quae cleopatrae unctus antonius est

quas 1

offertur

ibidem orationibus

parte erem1

vidisse

XXX iam per annos

hordiacio

cybra

sustentatur 10

Haec

videbuntur eis

reded am $^{11}$

centesimo tertio decimo

〈aetatis suae> anno

caelestem vitam

monachorum

adque 1111

multo meliorem

properare deberet. Illco

artos 12

media die

deducebatur

in deo meo

servum suum

conspicatur

mixtum

centauro

impraessionis signo

dei servus hic

erendens

satis

Et $\left\langle\right.$ cum dexterae ${ }^{13}$ manus protensione

10 corr. $2 \mathrm{~m} \bullet ;$, sustentantur" $1 \mathrm{~m}$.

11 "rededam" $1 \mathrm{~m} \bullet$; "redeam" $2 \mathrm{~m}$. corr.

$12{ }^{\circ{ }^{n} 2} \mathrm{~m}$. sup. ras.

132 "i" 2 m. sup. 1in. 
75. et sic patentes /7, 23/

76. haec utrum diabolus /7, 23/

77. animalium ferax /7, 23/

78. quoque $/ 7,23 /$

79. habemus $/ 7,23 /$

80. ot de eo /8, 23/

81. progreditur /8, 23/

82. saxosam convallem haud $/ 8,23 /$

83. adunct1s /8, 23/

84. asperata, cuius /8, 23/

85. Ad hoc Antonius spectaculum /8, 23/

86. scutum fidei et loricam spei, ut bonus $/ 8,23 /$

87. arripuit $/ 8,23 /$

88. palmarum fructus eidem ad $/ 8,23 /$

89. vocans colit /8, 23/

90. Legatione $/ 8,23-24 /$

91. Precamur $/ 8,24 /$

92. quem in salutem /8, 24/

93. et in universam terram /8, 24/

94. et de interitu $/ 8,24 /$

95. Intelligere /8, 24/

96. In quam /8, 24/

97. et tu pro Deo portenta veneraris $/ 8,24 /$

98. pennigero $/ 8,24 /$

99. cuiquam /8, 24/

100. Alexandriam $/ 8,24 /$

101. aestatis /8, 24/

102. Infuso, Antiochiam /8, 24/

103. coeptam regionem /9, 24/

104. nesciebat. Jam altera effluxerat $19,24 /$

105. secundas $/ 9,24 /$

106. sitis /9, 25/

107. anhelentem, ad $\operatorname{radicam} / 9,25 /$

108. et juxta /9, 25/

109. abiisset, accedens, intro coepit aspicere $/ 9,25 /$ ac si patentes

hoc utrum diabulus

ferax animalium

/om/

habimus

de eo

progrediebatur

saxosum convalle

aduncis

adsperata. Cui

Et hoc adtonitus expectaculo

scutum et loricam fidei, bonu

\section{arrepuit}

palmarum Pructum ad

colit

Legationem

praecamor

salutem

in universa 〈enim > terra

de interitu

intellegere

in qua

/om/

pinnigero

cui

alexandria

aestus

infusum $\langle e t>$ anthiocia

coepta regione

lam altera fluxerat

secundans

satis

anhelantem, ad radicem iuxta

abiit, 〈et $>$ accedens coepit introspicere 


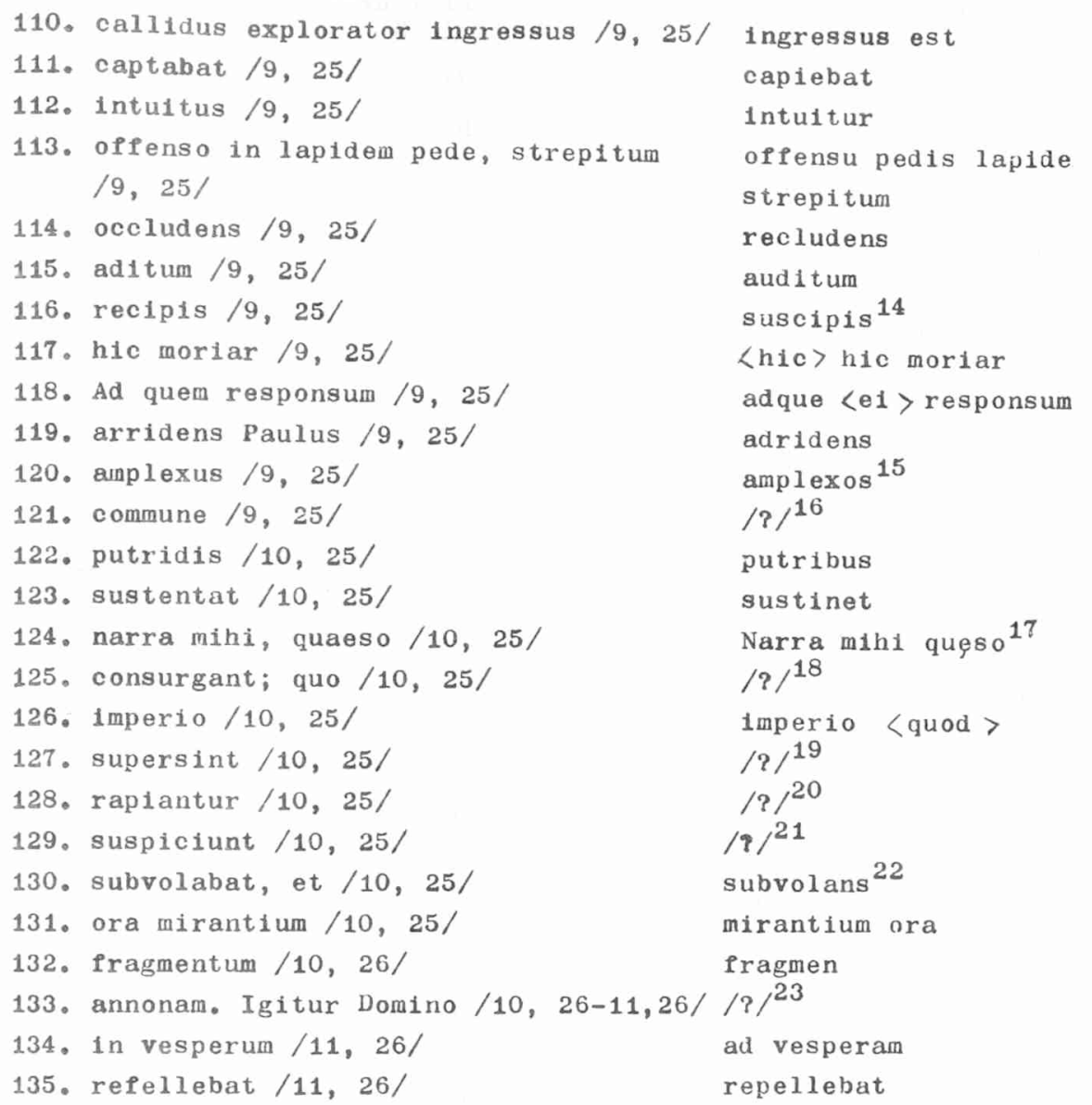

14 "suscipis"/ut vid./ sed minime legi potest.

15 "o" 2 m. sup. ras.

$16 \operatorname{leg} 1$ nequit.

17 corr. 2 m. sup. ras.

18 legi nequit; "quo" om./ut vid./.

19 legi nequit.

20 legi nequit.

21 legi nequit.

22 "et" om./ut. vid./; "et" legi nequit.

23 legi nequit. 
136. nititur /11, 26/

137. pars sua remaneret /11, 26/

138. Dehinc /11, 26/

139. paululum aquae in fonte prono ore $/ 11,26 /$

140. 1ibaverunt /11, 26/

141. esse terrae /11, 26/

142. te conservum /11, 26/

143. promiserat Deus: sed quia lam $/ 11,26 /$

144. dormitionis meae /11, 26/

145. peracto /11, 26/

146. corona justitiae: tu missus es a Domino /11, 26/

147. meum tegas, imo terrae terram $/ 11,26 /$

148. Illis /12, 26/

149. tale itineris / $12,26 /$

150. Et 111 e $/ 12,26 /$

151. Expedit tibi /12, 26/

152. quaeso, perge $/ 12,26 /$

153. magnopere $/ 12,26 /$

154. tanto temporis /12, 26/

155. a se recedenti moeror suae mortis levaretur /12, 26/

156. Saracenis /12, $26 /$

157. gressus $/ 12,26 /$

158. quamvis /12, 26/

159. Pregerant, tamen animo /12, 26/

160. Patigatus $/ 13,27 /$

161. qui ei jam $/ 13,27 /$ nititur ${ }^{24}\left\langle\right.$ trahere ${ }^{24}$

$/ ? / 25$

$/ ? / /^{26}$

paulolum aquae prono in $/ ? / 27$

ore

libarunt

esset terris

cons ervum

promiserat dominus. Sed quia

dormitionis

peractu

coronam iustitif. Tu missus

a domino es

tegas immo terram terrae

$/ ? / 28$

talis itineris

At $111 \mathrm{e}$

Expedit <quidem>tibi

perge quaeso

magno opere 29

tanti temporis

ad se recedens memoria suae

mortis relevaretur

sarracenis 30

gressos

cum

Prangerent animo

defatigatus

qui etiam

\section{4 corr. $2 \mathrm{~m} . \mathrm{sup}$, ras.}

$25 \operatorname{leg} 1$ nequit.

$26 \log 1$ nequit.

27 post ${ }^{1}$ " /ut vid./.

$28 \operatorname{leg} 1$ nequit.

29 "magno opere" $1 \mathrm{~m} \bullet$; "magnopere" $2 \mathrm{~m}$.

$30{ }^{11} \mathrm{ra}^{y} \mathrm{~m}$. $\mathrm{sup}$. $1 \mathrm{n}$. 
162. vidi Paulum in paradiso / $13,27 /$ 163. Et sic oro $/ 13,27 /$

164. ex cellula /13, $27 /$

165. Rogantibus $/ 13,27 /$

166. tacend 1 , et tempus loquendi $/ 13$, 167. regressus est $/ 14,27 /$

168. ac tota mente /14, 27/

169. quod et evenit /14, 27/

170. Christo debitum

171. al1a 1lluxisset/14, 27/

172. vidit inter /14, $27 /$

173. caternas $/ 14,27 /$

174. candore Paulum /14, 27/

175. In Paciem suam /14, 27/

176. superjaciebat, ploransque et ejulans, alebat /14, 27/

177. cur insalutatus abis /14, 27/

178. vidit genubus $/ 15,27 /$

179. Ac primum /15, $27 /$

180. vivere eum $/ 15,27 /$

181. ut nulla, ut $/ 15,27 /$

182. Poras corpore, hymnos quoque et psalmos de Christiana /16, 27/

183. decantans /16, $27 /$

184. non haberet. Fluctuans 1taque $/ 16,28 /$

185. reputans, dicebat $/ 16,28 /$

186. juxta bellatorem /16, 28/

187. halitum /16, 28/

188. eo animo volvente / $16,28 /$

189. Lubis $/ 16,28 /$

190. Rursusque $/ 16,28 /$

191. referens menten $/ 16,28 /$ in paradiso paulum vidi. Ac sic ore

e cella

rogantibusque

27/ loquendi et tempus tacendi regrediebatur

ac mente

quod evenit

debitum $x \bar{p} o$

inluxisset alia

videt inter

catervas

paulum candore

in Paciem

superiacebat, plorans adque eiulans

Cur habis ${ }^{31}$ insalutatus videt genibus

ac $^{32}$ primo

$<u t>$ vivere eum 33

nulla ut

corpore foras, psalmis

quoque xpTana

cantatis

non habebat. Fluctuans

reputans

<et > luxta bellatorem

anelitum

eo volvente

iuvis ${ }^{34}$

rursumque

mentem referens

31 „habis” 2 m. sup. lin.

32 "ac" $2 \mathrm{~m}$. sup. 1in.

33 "كut> vivere eum" $2 \mathrm{~m}$. corr.

34 corr. 2 m. sup. ras. 
192. prorsus ut intelligeres eos / 16,28

193. egerentes /16, 28/

194. unlus hominis / $16,28 /$

195. Poderunt. Ac /16, 28/

196. postulantes /16, $28 /$

197. At 1lle animadvertit /16, 28/

198. a se precari /16, 28/

199. In laudationem / $16,28 /$

200. Deum esse /16, 28/

201. cadit /16, 28/

202. annuens eis, ut $/ 16,28 /$

203. oneri / $16,28 /$

204. seniles /16, 28/

205. posuit $/ 16,28 /$

206. alla dies illuxit /16, 28/

207. tunicam eius sibi /16, 28/

208. 1pse sibi contexuerat /16, 28/

209. reversus /16, 28/

210. cuncta ex ordine $/ 16,28 /$

211. et Pentecostes /16, 28/

212. eos interrogare, qui sua patrimonia $/ 17,28 /$

213. P1lo/17, 28/

214. praedia /17, 28/

215. naturae concavis manibus satisfecit /17, 29/

216. quidem indumentum habuit mancipil vestri / $17,29 /$

217. vestem Christi /17, 29/

218. 11cet, tamen servavit /17, 29/

219. coopertus /17, 29/

220. in gloriam / 17, 29/

221. quaeso, vos $/ 17,30 /$ /om/

gerentes ${ }^{35}$

<quantum > unius hominis

effodere. Et

postulaturi

ut 111 e animadverteret 36

deprecare

$\langle\theta t\rangle$ in laudationem

/om/

cadet

innuens ut

honere ${ }^{37}$

senilis

conposuit

dies inluxerat alia

tunicam sibi eius

sibi ipse texuerat

regressus

ex ordine cuncta

uel penthecosten

interrogare eos qui patrian-

nia sua

lino

praetia

concavis manibus naturae satisfecit

quidem mancipil vestri

indumentum habuit

$x \bar{p} 1$ vestem

licet servabit

opertus

in gloria

quaeso, vobis

35 "gerentes"/ut vid./; legi minime potest.

36 "anim" 2 m. sup. $11 \mathrm{n}$.

371 , $\theta^{\text {" et }}$ "r" $2 \mathrm{~m}$. sup. ras. 
222. luctus $/ 17,30 /$

223. serico $/ 17,30 /$

224. poenis $/ 18,30 /$
1 uct os 38

sirico

meritis

Tak liczne warianty, znajdujące się w najstarszym rękopisie Vita S. Pauli primi eremitae, wskazują bez wątpienia, iz tekst tegoż dzieła w wydaniu Migne'a, bẹąc mało krytyczny, jest prawdopodobnie daleki od Hieronimowego oryginału i, co za tym idzie, porinien być zrewidowany i zastąpiony nowa krytyczną edycją.

\section{Bazyl1 Degórski OSPPE - Rzym}

\section{IL PIU' ANTICO TESTO
DELLA "VITA S. PAULI PRIMI EREMITAE"DI SAN GIROLAMO /Sommario/}

Delle tre biografie scritte da San Girolamo, la Vita S. Pauli è generalmente considerata la più antica; venne scritta prima del 380. Abbiamo sufficient1 ragioni autorevoli per credere che le copie della Vita vennero riprodotte molto presto. L'autore stesso parla di cio che fu forse la prima trascriziore di essa. Lo fa nella sua lettera a Paolo di Concordia al quale egli invio una copia della Vita Paul1. Possiamo giustamente supporre che egli non invio l'originale, ma una trascrizione di esso. San Girolamo era ben attrezzato per fare copie delle sue opere. Nella sua lettera a Florentinus egli dice che ha una grande biblioteca con un certo numero di amanuens1/ofr Ep. 5 , 2/. Un'altra prova che la Vita era largamente diffusa e quindi spesso copiata si trova nel prologo della Vita S. Hilarionis in cui Girolamo rimprovera alcuni critici malevoli della Vita S. Pauli. L'estesa critica starebbe ad indicare che esistevano folte copie della Vita. Fra 1 contemporanei di San Girolamo, Paolino, un diacono di Milano $/+418 /$, menziona la Vita nel prologo deila sua Vita S. Ambrosil. Molti scrittorl parlano di S. Paolo di Tebe senza menzionare la sua biografia, ma dato che San Girolamo è stato il primo a diffondere la conoscenza di Paolo in Occidente, possiamo inferire che sia scrittori contemporanei che posteri hanno ottenuto le loro informazioni direttamente da una copla della Vita. Molte copie della Vita fecero si che al testo originale entrarono delle varianti. Per tale ragione, tutti i codici piu antichi, che contengono la Vita S. Pauli, sono importantissimi per poter rintracciare 11 testo più vicino all'originale.

Il piu antico codice che contiene Vita S. Pauli Primi Eremitae è 11 Veronensis XXXVIII /36/, a. 517, $250 \mathrm{x} 224 \mathrm{~mm}$; $118 \mathrm{fog} 11,20$ linee, circa 31 lettere. E' 11 piu antico manoscritto in cartapecora 
al quale 10 scrivano abbia apposto una data definita. E' ancora a Verona, dove fu scritto, nella Biblioteca Capitolare di Verona. Possiede abbreviazioni di due tipi: q' per -que, ed una linea con un punto sopra, per $-\underline{m}$. Il $\log l 10112$ ando presto smarrito ma fu sostituito da una mano posteriore, probabilmente del nono secolo. Dato che non esiste alcuna edizione della Vita Pauli in cui le sottosezioni siano segnate o le righe numerate, nel presente articolo, elencando le varianti del Veronensis XXXVIII /36/, abbiamo usato il testo della Vita ricavato dalla Patrologia Latina del Migne/la prima cifra indica 11 capitolo, l'altra, invece, la colonna/. Tant\$ssime varianti, che troviamo nel Veronensis, stanno ad indicare che, senza dubbio, il testo della. Vita S. Pauli nella Patrologia Latina di Migne, essendo poco critico, è molto lontano dall'originale di Girolamo e, percio, dovrebbe essere riveduto e sostituito con una nuova edizione critica. 